University of Wollongong

Research Online

Australian Institute for Innovative Materials -

Papers

Australian Institute for Innovative Materials

2013

Correlation between structural parameters and the magnetocaloric effect in epitaxial La0.8Ca0.2MnO3/LaAlO3 thin film

J C. Debnath

University of Wollongong, jcd341@uow.edu.au

J H. Kim

University of Wollongong, jhk@uow.edu.au

Y Heo

Pohang University of Science and Technology

A M. Strydom

University of Johannesburg

S X. Dou

University of Wollongong, shi@uow.edu.au

Follow this and additional works at: https://ro.uow.edu.au/aiimpapers

Part of the Engineering Commons, and the Physical Sciences and Mathematics Commons

Research Online is the open access institutional repository for the University of Wollongong. For further information contact the UOW Library: research-pubs@uow.edu.au 


\title{
Correlation between structural parameters and the magnetocaloric effect in epitaxial La0.8Ca0.2MnO3/LaAlO3 thin film
}

\author{
Abstract \\ An epitaxial La0.8Ca0.2MnO3/LaAIO 3 (LCMO/LAO) thin film was fabricated using the pulsed laser \\ deposition technique to evaluate the correlation between the crystal structure and the magnetocaloric \\ effect. In our study, the LCMO film was $200 \mathrm{~nm}$ in thickness and appeared to have a strong out-of plane \\ texture. We found that each column in the LCMO thin film layer is a domain which has a different ordering \\ direction. These microscopic feature results in anisotropic properties of magnetization, entropy, and \\ relative cooling power. The film exhibited a paramagnetic-to-ferromagnetic second order phase transition \\ at $249 \mathrm{~K}$. The lack of any hysteresis loss also confirmed that the material is intrinsically reversible. In \\ addition, the large magnetization of the thin film results in an entropy change larger than those of all other \\ perovskite type materials. Consequently, the relative cooling power is significantly enhanced.

\section{Keywords} \\ between, effect, epitaxial, structural, film, correlation, thin, la0, laalo3, 2mno3, 8ca0, parameters, \\ magnetocaloric

\section{Disciplines} \\ Engineering | Physical Sciences and Mathematics

\section{Publication Details} \\ Debnath, J. C., Kim, J. H., Heo, Y., Strydom, A. M. \& Dou, S. X. (2013). Correlation between structural

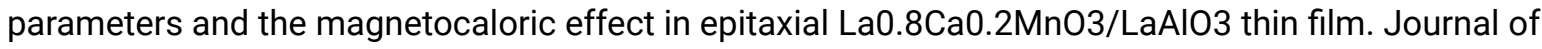 \\ Applied Physics, 113 (6), 063508-1-063508-6.
}


AIP Applied Physics

Correlation between structural parameters and the magnetocaloric effect in epitaxial La0.8Ca0.2MnO3/LaAlO3 thin film

J. C. Debnath, J. H. Kim, Y. Heo, A. M. Strydom, and S. X. Dou

Citation: J. Appl. Phys. 113, 063508 (2013); doi: 10.1063/1.4790876

View online: http://dx.doi.org/10.1063/1.4790876

View Table of Contents: http://jap.aip.org/resource/1/JAPIAU/v113/i6

Published by the American Institute of Physics.

\section{Related Articles}

Age splitting of the $\mathrm{La}(\mathrm{Fe} 1-\mathrm{xSix}) 13 \mathrm{Hy}$ first order magnetocaloric transition and its thermal restoration J. Appl. Phys. 113, 17 A908 (2013)

Effect of crystallographic alignment on the magnetocaloric effect in alloys near the Ni2MnGa stoichiometry J. Appl. Phys. 113, 17A907 (2013)

Normal and inverse magnetocaloric effects in ferromagnetic Pr0.58Sr0.42MnO3

J. Appl. Phys. 113, 17A906 (2013)

Large reversible magnetocaloric effects in ErFeSi compound under low magnetic field change around liquid hydrogen temperature

Appl. Phys. Lett. 102, 092401 (2013)

Investigation of the critical behavior in $\mathrm{Mn} 0.94 \mathrm{Nb} 0.06 \mathrm{CoGe}$ alloy by using the field dependence of magnetic entropy change

J. Appl. Phys. 113, 093902 (2013)

\section{Additional information on J. Appl. Phys.}

Journal Homepage: http://jap.aip.org/

Journal Information: http://jap.aip.org/about/about_the_journal

Top downloads: http://jap.aip.org/features/most_downloaded

Information for Authors: http://jap.aip.org/authors

\section{ADVERTISEMENT}

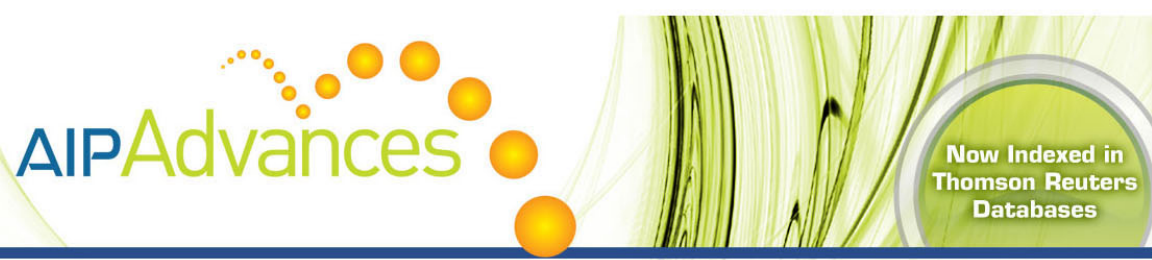

\section{Explore AIP's open access journal: - Rapid publication \\ - Article-level metrics \\ Post-publication rating and commenting}




\title{
Correlation between structural parameters and the magnetocaloric effect in epitaxial $\mathrm{La}_{0.8} \mathrm{Ca}_{0.2} \mathrm{MnO}_{3} / \mathrm{LaAlO}_{3}$ thin film
}

\author{
J. C. Debnath, ${ }^{1,3, a)}$ J. H. Kim, ${ }^{1}$ Y. Heo, ${ }^{2}$ A. M. Strydom, ${ }^{3}$ and S. X. Dou ${ }^{1}$ \\ ${ }_{1}^{1}$ Institute for Superconducting and Electronic Materials, University of Wollongong, Squaire Way, \\ North Wollongong, Wollongong, NSW 2500, Australia \\ ${ }^{2}$ Research Facility Center, Graduate Institute of Ferrous Technology, Pohang University of Science \\ Technology, Pohang, Kyungbuk 790-784, South Korea \\ ${ }^{3}$ Department of Physics, University of Johannesburg, PO Box 524, Auckland Park 2006, South Africa
}

(Received 14 December 2012; accepted 22 January 2013; published online 12 February 2013)

\begin{abstract}
An epitaxial $\mathrm{La}_{0.8} \mathrm{Ca}_{0.2} \mathrm{MnO}_{3} / \mathrm{LaAlO}_{3}$ (LCMO/LAO) thin film was fabricated using the pulsed laser deposition technique to evaluate the correlation between the crystal structure and the magnetocaloric effect. In our study, the LCMO film was $200 \mathrm{~nm}$ in thickness and appeared to have a strong out-of plane texture. We found that each column in the LCMO thin film layer is a domain which has a different ordering direction. These microscopic feature results in anisotropic properties of magnetization, entropy, and relative cooling power. The film exhibited a paramagnetic-toferromagnetic second order phase transition at $249 \mathrm{~K}$. The lack of any hysteresis loss also confirmed that the material is intrinsically reversible. In addition, the large magnetization of the thin film results in an entropy change larger than those of all other perovskite type materials. Consequently, the relative cooling power is significantly enhanced. (C) 2013 American Institute of Physics. [http://dx.doi.org/10.1063/1.4790876]
\end{abstract}

\section{INTRODUCTION}

Compressorless refrigeration represents one of future energy saving innovations. Magnetic refrigeration, based on large thermal changes driven by a magnetic field, is an important development in the quest for energy-efficient and environmentally friendly technologies. Materials exhibiting the giant magnetocaloric effect (MCE) have demonstrated potential for advancing magnetic refrigeration, a considerable socioeconomic benefited alternative to conventional refrigeration. ${ }^{1,2}$ Since the discovery of the giant MCE phenomenon, giant MCE has been found in a large variety of magnetic materials, including $\mathrm{Gd}, \mathrm{Gd}_{5}\left(\mathrm{Si}_{\mathrm{x}} \mathrm{Ge}_{1-\mathrm{x}}\right)_{4}, \mathrm{MnAs}_{1-\mathrm{x}} \mathrm{Sb}_{\mathrm{x}}, \mathrm{MnFe}\left(\mathrm{P}_{1-\mathrm{x}} \mathrm{As}_{\mathrm{x}}\right)$, $\mathrm{La}\left(\mathrm{Fe}_{13-\mathrm{x}} \mathrm{Si}_{\mathrm{x}}\right.$ ), and $\mathrm{RM}_{2}$ (where $\mathrm{R}=$ rare earth, $\mathrm{M}=\mathrm{Al}$, Co, Ni). ${ }^{3-8}$ Further efforts to discover new materials, especially materials without rare-earth elements and exhibiting large $\mathrm{MCE}$ in response to low applied field, are of significant importance. Among them, perovskite-type manganese oxide materials having large MCE are believed to be potential candidates for magnetic refrigeration applications. ${ }^{9-16}$

In particular, the lanthanum manganite $\left(\mathrm{LaMnO}_{3}\right)$ family shows the perovskite structure. Here, the transition metal atoms of pure lanthanum manganite are predominantly in the state $\mathrm{Mn}^{3+}$. Upon substitution of a divalent ion (such as $\mathrm{Ca}^{2+}$, $\mathrm{Ba}^{2+}$, or $\mathrm{Sr}^{2+}$ ) on the rare earth site, an equal number of $\mathrm{Mn}^{4+}$ ions are created at the expense of $\mathrm{Mn}^{3+}$. The resulting compound can then be written, for instance, in the case of $\mathrm{Ca}$ substitution, as $\left(\mathrm{La}_{1-x}\right)^{3+}\left(\mathrm{Ca}_{x}\right)^{2+}\left(\mathrm{Mn}_{1-x}\right)^{3+}\left(\mathrm{Mn}_{x}\right)^{4+}$. The intricate magnetic behavior of this compound is determined by the nature of the magnetic interactions between the mixed valence Mn ions. Very recently, the thin film structure has

\footnotetext{
${ }^{\text {a) }}$ Author to whom correspondence should be addressed. Electronic mail: jcd341@uowmail.edu.au.
}

been receiving increased attention because it is easy to integrate into electronic structures for applications. ${ }^{17}$

Interest in lanthanum manganite has been rekindled in the last few years due to the observation of large magnetoresistance in films deposited by pulsed laser deposition. Thin films of La-Ca-Mn-O, ${ }^{18-21} \mathrm{La}-\mathrm{Ba}-\mathrm{Mn}-\mathrm{O},{ }^{22} \mathrm{La}-(\mathrm{Ca}, \mathrm{Pb})-\mathrm{Mn}-$ $\mathrm{O},{ }^{23} \mathrm{La}-\mathrm{Ce}-\mathrm{Mn}-\mathrm{O},{ }^{24}$ and $\mathrm{La}-\mathrm{Sr}-\mathrm{Mn}-\mathrm{O}^{25}$ exhibit magnetoresistance in the range of $5 \%-150 \%$, which is comparable to that obtained in giant magnetoresistance (GMR) metal multilayers. Jin et al. and McCormack et al. reported $^{26,27}$ a "colossal" magnetoresistance of more than $100000 \%$ for epitaxial La-Ca-Mn-O films on $\mathrm{LaAlO}_{3}$. The origin of these enormous magnetoresistance values is unknown, although they evidently are related to the magnetic state of the system. The very large magnetization obtainable in this system near room temperature has also led us to study the magnetocaloric behavior of doped $\mathrm{LaMnO}_{3}$ films.

It should be mentioned that most of today's research activity in this field is limited to bulk and single crystal perovskite-type manganese oxide materials, but studies on thin film for MCE are very limited. Recently, scientists have started doing research on the MCE properties of thin films, but only a few reports are currently available, ${ }^{28-33}$ although in principle, such films will be easier to integrate into electronic structures for applications. ${ }^{17}$

However, with the currently available magnetic materials, this high efficiency is only realized in high magnetic fields. Nanostructuring is a promising route to perturb properties and may lead to novel and advantageous magnetocaloric properties using existing materials. As $\mathrm{La}_{0.8} \mathrm{Ca}_{0.2} \mathrm{MnO}_{3}$ (LCMO) is traditionally the standard by which all perovskitetype manganese oxide materials are measured, we have begun investigating the impact of nanostructuring using $\mathrm{La}_{0.8} \mathrm{Ca}_{0.2} \mathrm{MnO}_{3}$ thin film with a simple monoclinic structure. 
In this work, we fabricated an epitaxial $\mathrm{La}_{0.8} \mathrm{Ca}_{0.2} \mathrm{MnO}_{3} /$ $\mathrm{LaAlO}_{3}$ (LCMO/LAO) thin film by pulsed laser deposition (PLD). It is speculated that this structure would help to improve the performance of the materials by maximizing the entropy change, suppressing hysteresis losses, adjusting the operation temperature, and reducing the required magnetic field. ${ }^{34}$ In addition, thin films show phase diagrams that are much richer than those for the corresponding bulk materials. This is because thin films emerge with two additional external variables, i.e., the film thickness and the epitaxial stress caused by lattice mismatch between the film and the substrate. The epitaxial strain in thin films can change the Jahn-Teller (JT) distortions of $\mathrm{Mn}^{3+} \mathrm{O}_{6}$ octahedra, leading to strong electronphonon coupling, which may produce substantial effects that act on various aspects of the film, including the growth mode, imperfections, and the associated structural and physical properties. ${ }^{35,36}$ Therefore, it is necessary to evaluate the correlation between the MCE and the microstructure in detail.

While a wide range of materials have been studied thus far, magnetocaloric materials have been largely unexplored on the nanoscale. Because nanostructuring is a well known approach used to perturb and tune structure-property relationships, ${ }^{37}$ associated techniques are being applied to study the MCE in nanoparticles and thin films. ${ }^{38,39}$ In this sense, the study of MCE in LCMO thin film is of great interest for testing the viability of LCMO as the nucleus of refrigeration systems.

\section{EXPERIMENTAL DETAILS}

The epitaxial LCMO film $(\sim 200 \mathrm{~nm})$ was grown on a (100) $\mathrm{LaAlO}_{3}$ substrate by $\mathrm{PLD}^{40}$ at Institute for Superconducting and Electronic Materials (ISEM), University of Wollongong, Australia. A short pulse excimer laser $(\lambda=248 \mathrm{~nm})$ was focused onto a stoichiometric LCMO target with an estimated energy density of $\sim 3.2 \mathrm{Jcm}^{-2}$ and a repetition rate of $5 \mathrm{~Hz}$. The oxygen pressure in the deposition chamber was kept at 300 mTorr, while the temperature of the substrate was maintained at $800{ }^{\circ} \mathrm{C}$ during the preparation process. The film thickness was controlled by the deposition time, which was at a rate of $50 \mathrm{~nm} / \mathrm{min}$. Following the deposition, the film was cooled to room temperature over $2 \mathrm{~h}$ in an oxygen atmosphere without any further thermal treatment.

For transmission electron microscopy (TEM), a thin sample was prepared by ion milling in a JEOL JEM-9320FIB. The sample was attached to a molybdenum TEM grid. This film was observed in a transmission electron microscope (JEOL JEM-2100F) equipped with energy dispersive spectroscopy (EDS). The epitaxial and lattice parameters of the film were examined and calculated from the data obtained using X-ray diffraction. Magnetization measurements were performed using a physical properties measurement system (PPMS) with a $14 \mathrm{~T}$ magnetometer in the temperature range from 5 to $300 \mathrm{~K}$ and magnetic fields up to $5 \mathrm{~T}$. To measure the magnetic entropy change, $\Delta \mathrm{S}_{\mathrm{M}}$, from $\mathrm{M}(\mathrm{H})$ plot, we used a sweep rate of $50 \mathrm{Oe} / \mathrm{s}$.

\section{RESULT AND DISCUSSION}

Figure 1(a) shows the X-ray diffraction pattern of a $\mathrm{La}_{0.8} \mathrm{Ca}_{0.2} \mathrm{MnO}_{3}$ film deposited on $\mathrm{LaAlO}_{3}$ substrate. It appears to have a strong out-of plane texture, reflecting $(00 l)$. It is well known that thin film quality can be basically evaluated by the full-width at half maximum (FWHM) of important peaks. The corresponding FWHMs of the (002) and (004) peaks were $0.1340^{\circ}$ and $0.2620^{\circ}$, respectively, for $\mathrm{La}_{0.8} \mathrm{Ca}_{0.2} \mathrm{MnO}_{3}$ thin film on the $\mathrm{LaAlO}_{3}$ substrate ( $a=3.79 \AA)$, indicating the excellent $c$-axis orientation of all the films. In addition, the crystal structure of our sample is exactly matched with the monoclinic structure $(a=7.75 \AA$, $b=7.745 \AA, c=7.75 \AA$ ) from X-ray refinement analysis. A cross-sectional view is also shown in Figure 1(b). We observe that the interface between the substrate and the film is relatively uniform and sharp. The thickness of the $\mathrm{La}_{0.8} \mathrm{Ca}_{0.2} \mathrm{MnO}_{3}$ layer was estimated to be $200 \mathrm{~nm}$. To further clarify, there still needs to be deeper insight from the viewpoint of microstructure.

Figure 2(a) shows a TEM bright field image of a $\mathrm{La}_{0.8} \mathrm{Ca}_{0.2} \mathrm{MnO}_{3} / \mathrm{LaAlO}_{3}$ thin film. Electron diffraction patterns were acquired from the $\mathrm{La}_{0.8} \mathrm{Ca}_{0.2} \mathrm{MnO}_{3}$, the $\mathrm{LaAlO}_{3}$, and the interface area, and the results are displayed in Figures 2(b)-2(d), respectively. Comparing the image in Figure 2(a) and the electron diffraction pattern in Figure 2(b), it is clear that the $\mathrm{La}_{0.8} \mathrm{Ca}_{0.2} \mathrm{MnO}_{3}$ layer grew in the [001] direction. Here, an orientation relationship between $\mathrm{La}_{0.8} \mathrm{Ca}_{0.2} \mathrm{MnO}_{3}$ and $\mathrm{LaAlO}_{3}$ exists and is given by
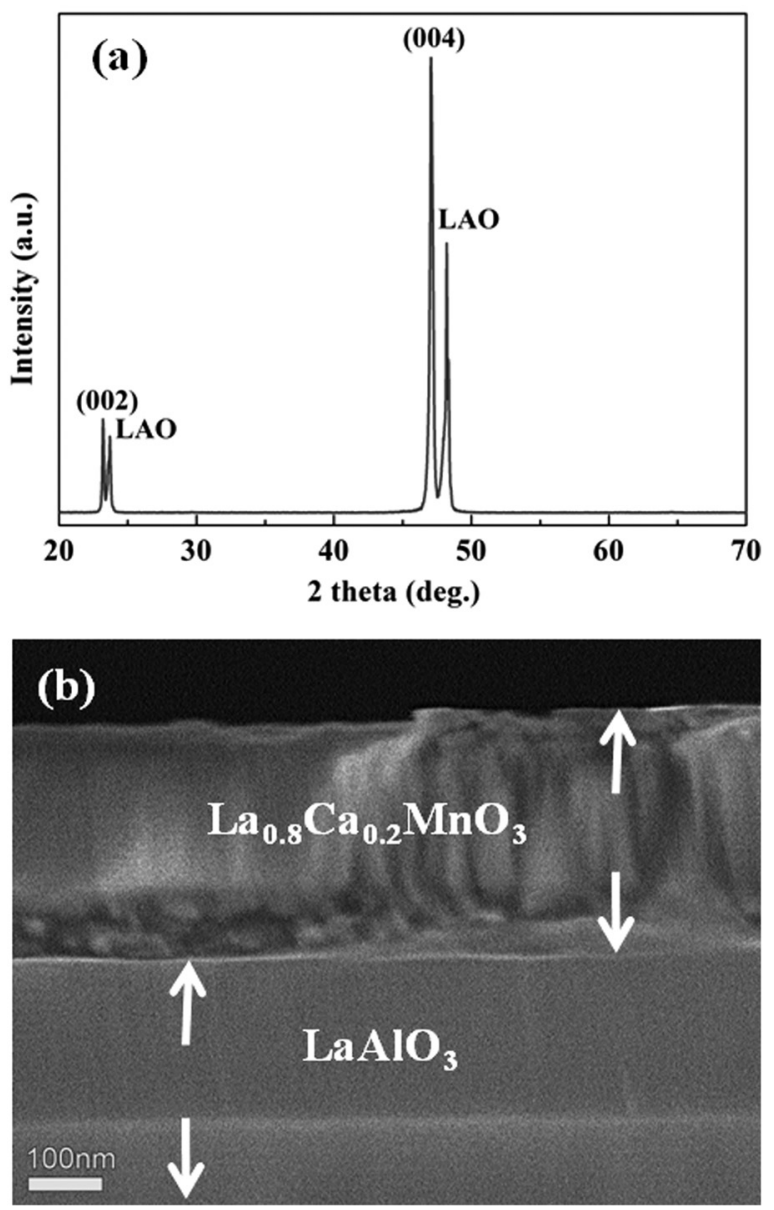

FIG. 1. (a) XRD pattern of the film grown on LAO showing $(00 l)$ peaks of the orthorhombic structure. (b) Cross-sectional SEM image of the film showing the epitaxial nature and columnar grain growth. 

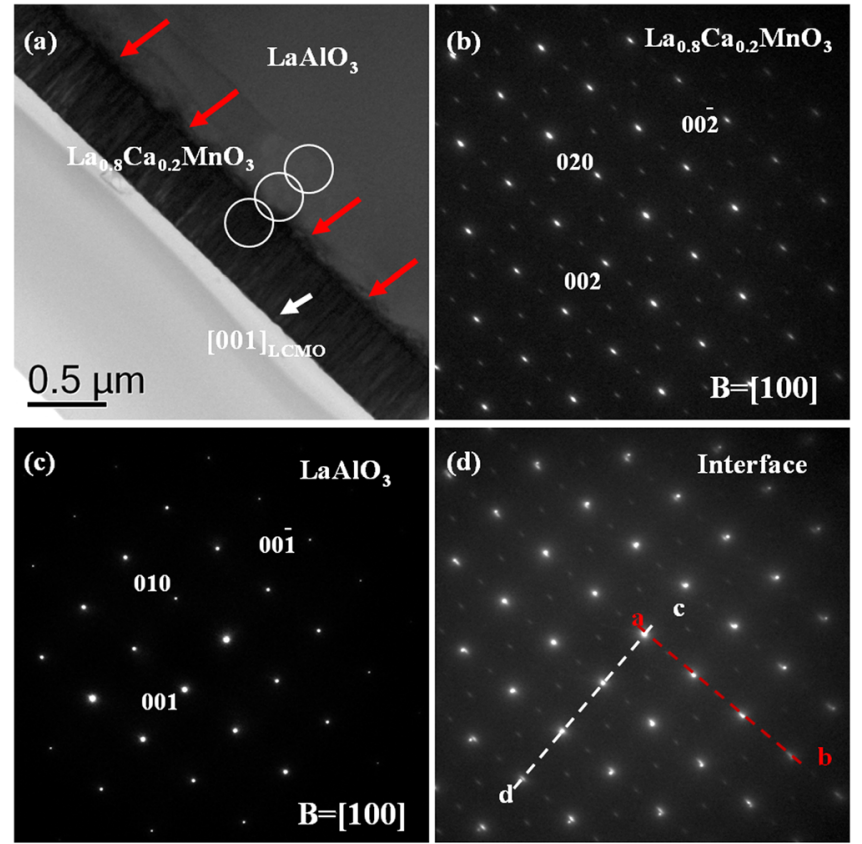

(e)

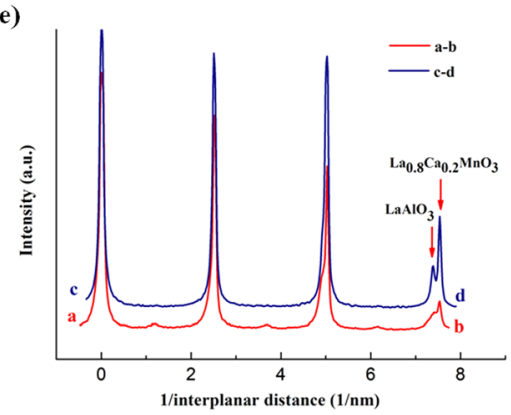

FIG. 2. (a) TEM bright field image of $\mathrm{La}_{0.8} \mathrm{Ca}_{0.2} \mathrm{MnO}_{3} / \mathrm{LaAlO}_{3}$ thin film, with red arrows marking areas of dark contrast in the substrate where strain is present around misfit dislocations. Electron diffraction patterns of (b) $\mathrm{La}_{0.8} \mathrm{Ca}_{0.2} \mathrm{MnO}_{3}$, (c) $\mathrm{LaAlO}_{3}$, and (d) an interface area, respectively. The actual intensity profiles of the white and red dashed lines in (d) are displayed in (e).

$$
\begin{gathered}
\quad[100]_{\mathrm{La}_{0.8} \mathrm{Ca}_{0.2} \mathrm{MnO}_{3}} / /[100]_{\mathrm{LaAlO}_{3}}, \\
{[010]_{\mathrm{La}_{0.8} \mathrm{Ca}_{0.2} \mathrm{MnO}_{3}} / /[010]_{\mathrm{LaAlO}_{3}},} \\
\text { and }[001]_{\mathrm{La}_{0.8} \mathrm{Ca}_{0.2} \mathrm{MnO}_{3}} / /[001]_{\mathrm{LaAlO}_{3}}
\end{gathered}
$$

The lattice parameters of $\mathrm{La}_{0.8} \mathrm{Ca}_{0.2} \mathrm{MnO}_{3}$ are almost double those of the $\mathrm{LaAlO}_{3}$ substrate, as mentioned above. However, lattice misfit between the two phases exists, and this is responsible for the elongated diffraction spots in Figure 2(d). The actual intensity profiles of the white and red dashed lines in Figure 2(d) are displayed in Figure 2(e). The profiles have two maximum points, as indicated by the red arrows. Because this diffraction pattern was taken from the interface of two phases, one of the maximum points comes from $\mathrm{La}_{0.8} \mathrm{Ca}_{0.2} \mathrm{MnO}_{3}$ and the other comes from $\mathrm{LaAlO}_{3}$. We calculated lattice misfit at the $\mathrm{La}_{0.8} \mathrm{Ca}_{0.2} \mathrm{MnO}_{3} / \mathrm{LaAlO}_{3}$ interface from the distances (R) of peaks in Figure 2(e). Lattice misfit can be calculated by $\left(D_{\text {film }}-D_{\text {substrate }}\right) / D_{\text {substrate }} \times 100=\left(1 / R_{\text {film }}-1 / R_{\text {substrate }}\right) /$ $\left(1 / R_{\text {substrate }}\right) \times 100=\left(\left(R_{\text {substrate }} / R_{\text {film }}\right)-\right) \times 100$, where $D$ is the interplanar distance. The calculated value is about $1.9 \%$. This large lattice misfit is responsible for the misfit dislocation at the $\mathrm{La}_{0.8} \mathrm{Ca}_{0.2} \mathrm{MnO}_{3} / \mathrm{LaAlO}_{3}$ interface. The existence of misfit dislocations at the $\mathrm{La}_{0.8} \mathrm{Ca}_{0.2} \mathrm{MnO}_{3} / \mathrm{LaAlO}_{3}$ interface was reported by Daoudi et al. ${ }^{41}$ It was explained that the misfit dislocation releases the lattice misfit strain at the interface. Even though a misfit dislocation releases misfit strain, there is a strain field in the areas around the misfit dislocations. In the TEM bright field image, we can find these contrasts when we compare the $\mathrm{La}_{0.8} \mathrm{Ca}_{0.2} \mathrm{MnO}_{3} / \mathrm{LaAlO}_{3}$ interface image in Figure 2(a) with that of Figure 1(b); irregular contrast at the interface in Figure 2(a) is attributable to the strain field around interface. Interestingly, the dark contrasts show up in the $\mathrm{LaAlO}_{3}$ substrate, as marked with red arrows.

The magnified columnar structure of the $\mathrm{La}_{0.8} \mathrm{Ca}_{0.2} \mathrm{MnO}_{3}$ thin film is shown in Figure 3. The size of each column was estimated to be about $30 \mathrm{~nm}$. The annular dark field scanning TEM (ADF-STEM) image in Figure 3(b) clearly reveals the existence of dislocations around $\mathrm{La}_{0.8} \mathrm{Ca}_{0.2} \mathrm{MnO}_{3} / \mathrm{LaAlO}_{3}$ interface where there are areas of dark contrast in Figure 2(a). Interestingly, it is clear that all the dislocations are located in the $\mathrm{LaAlO}_{3}$ substrate region. This suggests that the $\mathrm{LaAlO}_{3}$
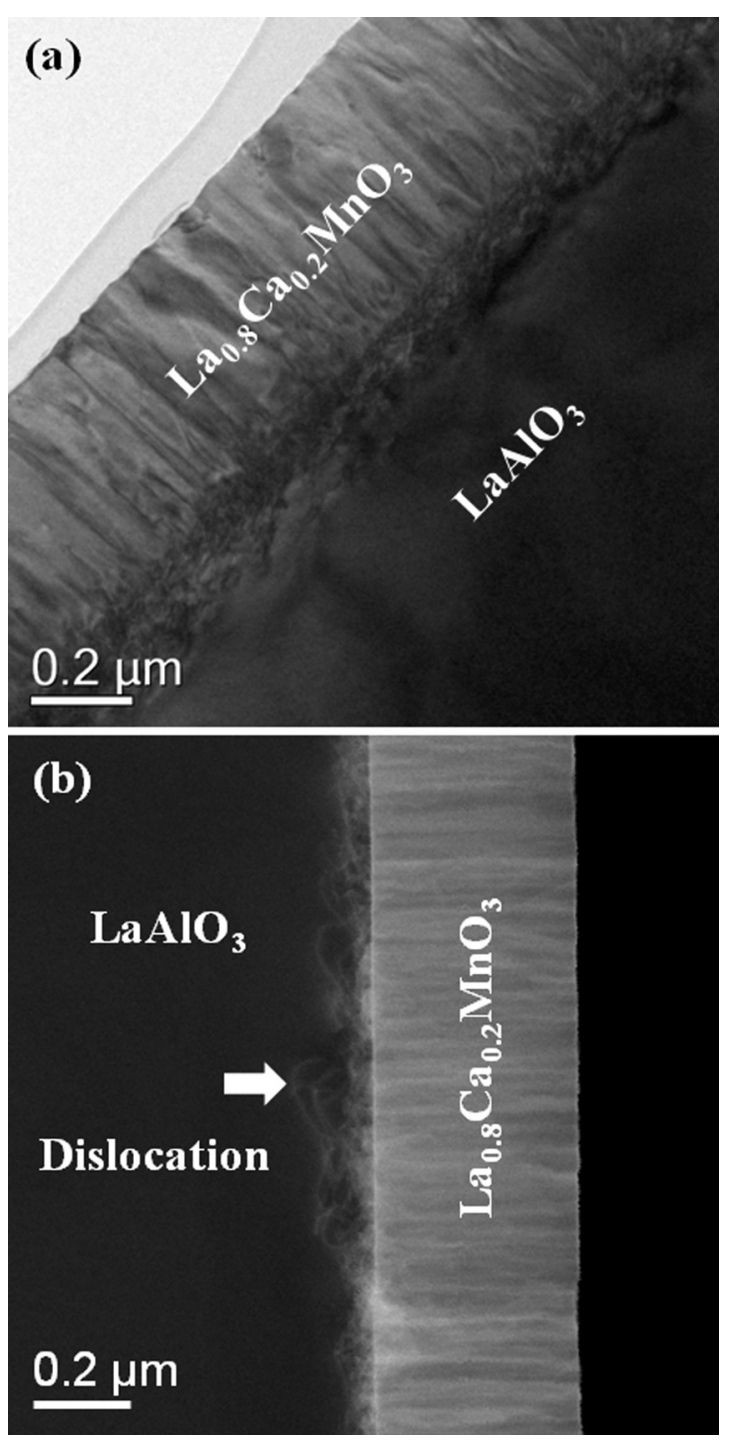

FIG. 3. (a) High magnification TEM image of $\mathrm{La}_{0.8} \mathrm{Ca}_{0.2} \mathrm{MnO}_{3} / \mathrm{LaAlO}_{3}$ thin film. (b) ADF-STEM image; dislocations are generated in the $\mathrm{LaAlO}_{3}$ substrate. 
substrate accommodates lattice misfit strain between $\mathrm{La}_{0.8} \mathrm{Ca}_{0.2} \mathrm{MnO}_{3}$ and $\mathrm{LaAlO}_{3}$.

Figure 4(a) shows a bright field (BF) image of a $\mathrm{La}_{0.8} \mathrm{Ca}_{0.2} \mathrm{MnO}_{3} / \mathrm{LaAlO}_{3}$ thin film. There are many columns in the $\mathrm{La}_{0.8} \mathrm{Ca}_{0.2} \mathrm{MnO}_{3}$ thin film layer. We investigated a high resolution image of the interface, which is denoted by the rectangle in Figure 4(a), between two neighboring columns (Figure 4(b)). The fast Fourier transform (FFT) patterns of selected areas 1 and 2 are displayed in Figures 4(c) and 4(d), respectively. These two patterns clearly show that these two areas are not different grains but different domains. The domains are ordered perpendicular each other. Therefore, each column in the $\mathrm{La}_{0.8} \mathrm{Ca}_{0.2} \mathrm{MnO}_{3}$ thin film layer is a domain which has a different ordering direction. The existence of domain structures in $\mathrm{La}_{0.8} \mathrm{Ca}_{0.2} \mathrm{MnO}_{3}$ thin film has been previously reported. ${ }^{42}$ To confirm the domain structure, we analyzed two adjacent columns by the nanobeam diffraction method. The beam size was $1.6 \mathrm{~nm}$, so that the size was sufficient to acquire information from only one column. Figures 4(e) and 4(f) show the results. These results are in agreement with those of the high resolution analysis in Figures 4(c) and 4(d).
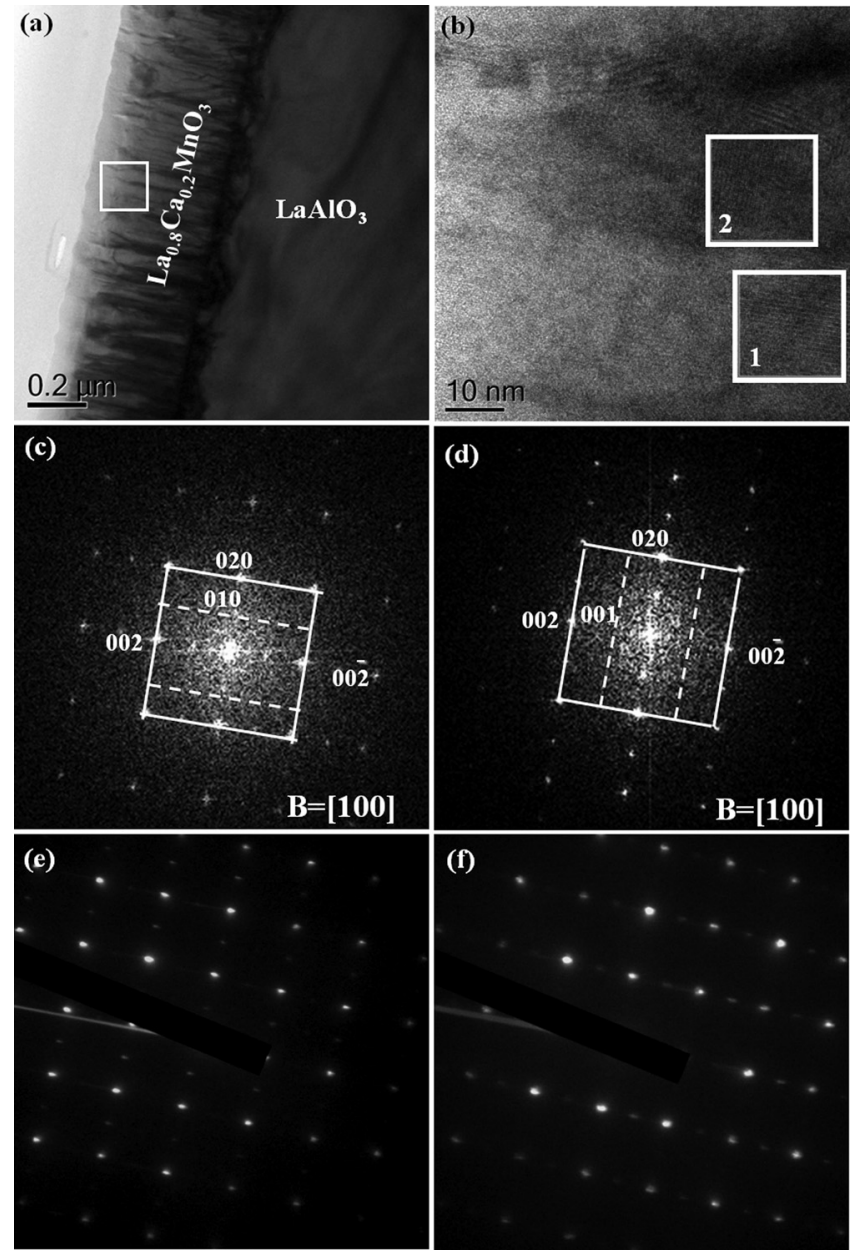

FIG. 4. (a) Bright field image of $\mathrm{La}_{0.8} \mathrm{Ca}_{0.2} \mathrm{MnO}_{3} / \mathrm{LaAlO}_{3}$ thin film. (b) High resolution image of the interface between two neighboring columns is denoted by the rectangle in (a). The FFT patterns of selected areas 1 and 2 are displayed in (c) and (d), respectively. Beam diffraction patterns of two adjacent columns (e) and (f).
Figure 5(a) shows the temperature dependence of the magnetization (M-T) for different field directions. The Curie temperature $\left(\mathrm{T}_{\mathrm{C}}\right)$ was estimated to be $249 \mathrm{~K}$. In the literature, the $\mathrm{T}_{\mathrm{C}}$ values of bulk specimens and single crystals with the same composition were around 230 and $176 \mathrm{~K}$, respectively, ${ }^{43,44}$ It is noteworthy that there is a drastic change in the magnetization around $\mathrm{T}_{\mathrm{C}}$ in the $a b$ plane $(\mathrm{H} / / \mathrm{ab})$. However, the magnetization along the $c$-axis $(\mathrm{H} / / \mathrm{c})$ seems to be insensitive to increasing temperature. This is mainly due to the columnar structure of $c$-axis alignment observed in the TEM. So it seems that magnetization in the ab plane $(\mathrm{H} / / \mathrm{ab})$ is the easy and $c$-axis $(\mathrm{H} / / \mathrm{c})$ is the hard direction of magnetization for the thin film. Hysteresis loops $(\mathrm{M}-\mathrm{H})$ of the thin film are also shown in Figure 5(b). Interestingly, there is no magnetic hysteresis, which indicates that the MCE is fully reversible and confirms the second-order character of the ferromagnetic-paramagnetic (FM-PM) transition. We also collected initial magnetization isotherms in the vicinity of $\mathrm{T}_{\mathrm{C}}$. From the Banerjee criterion, ${ }^{45}$ the phase transition of our thin film appears typically second order. We also confirmed that $\mathrm{T}_{\mathrm{C}}$ is approximately $249 \mathrm{~K}$ from Arrott plots (not shown). This is quite comparable with the results shown in Figure 5(a).

The magnetic entropy changes in the $\mathrm{La}_{0.8} \mathrm{Ca}_{0.2} \mathrm{MnO}_{3}$ thin film for different magnetic field directions are shown in Figure 6. $\left|\Delta \mathrm{S}_{\mathrm{M}}\right|$ shows a peak with its maximum around $247 \mathrm{~K}$ near $\mathrm{T}_{\mathrm{C}}$. The maximum values of $\left|\Delta \mathrm{S}_{\mathrm{M}}\right|$ were estimated
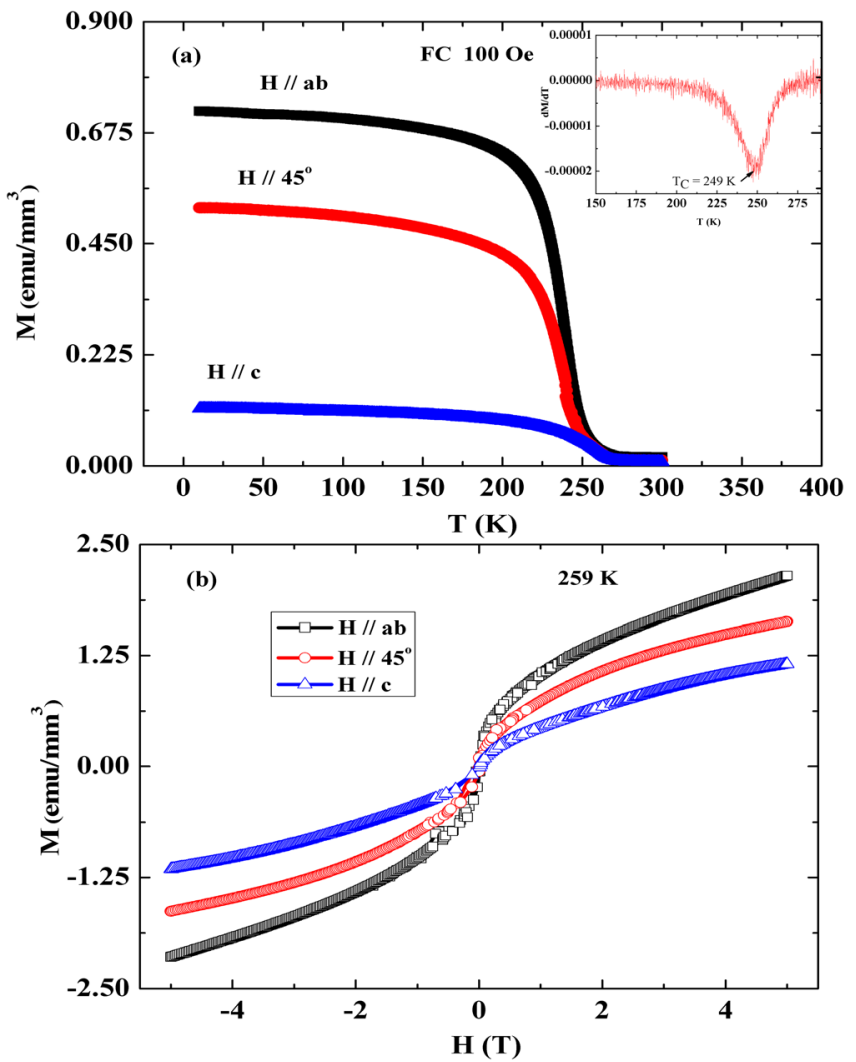

FIG. 5. (a) Temperature dependence of the magnetization (M-T curves) along the $a b$-plane, at a $45^{\circ}$ angle to the $a b$-plane, and in the $c$-direction for the $\mathrm{La}_{0.8} \mathrm{Ca}_{0.2} \mathrm{MnO}_{3}$ thin film. The inset shows $\mathrm{dM} / \mathrm{dT}$ versus $\mathrm{T}$ used for the determination of $\mathrm{T}_{\mathrm{C}}$. (b) $\mathrm{M}-\mathrm{H}$ hysteresis loops measured at a temperature of $259 \mathrm{~K}$ for all directions. 


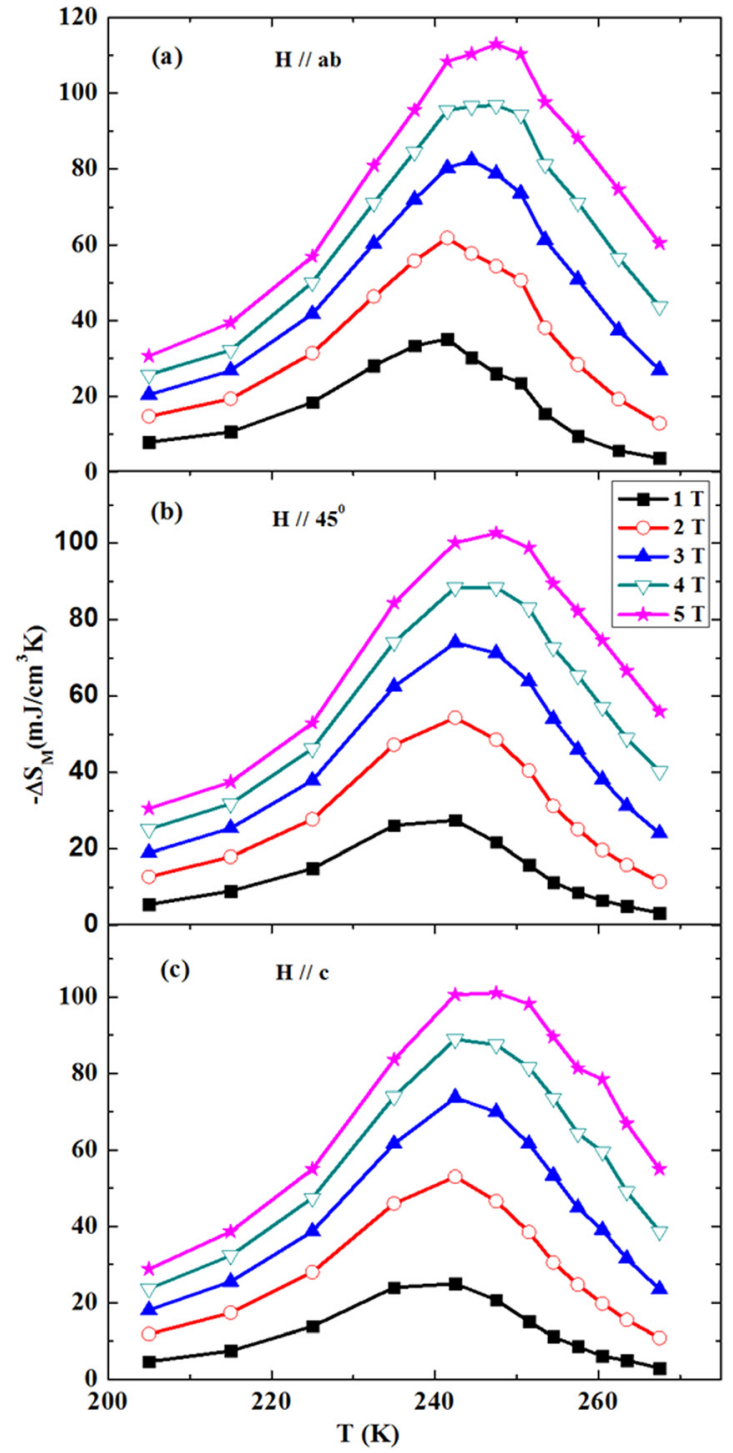

FIG. 6. Magnetic entropy change as a function of temperature and change in magnetic field $\Delta \mathrm{H}$, as indicated in the legend, with different field directions.

to be $35.90,27.50$, and $24.97 \mathrm{mJcm}^{-3} \mathrm{~K}^{-1}$ under a field change of $1 \mathrm{~T}$ for the different field directions, $\mathrm{H} / / \mathrm{ab}, \mathrm{H} / / 45^{\circ}$, and $\mathrm{H} / / \mathrm{c}$, respectively. Corresponding values were 112.9 , 102.6, and $101 \mathrm{mJcm}^{-3} \mathrm{~K}^{-1}$ under a $5 \mathrm{~T}$ magnetic field change. What is interesting is that a large low-field magnetic entropy change along the $a b$-plane is observed. The maximum values of $\left|\Delta \mathrm{S}_{\mathrm{M}}\right|$ are about 35.9 and $61.18 \mathrm{mJcm}^{-3} \mathrm{~K}^{-1}$ for a magnetic field change of $1 \mathrm{~T}$ and $2 \mathrm{~T}$, respectively. These values of $\left|\Delta S_{M}\right|$ are on the same order of magnitude as that of $\mathrm{Gd}^{46}$ and are even higher than in many perovskite manganites. $^{43,44}$ These low-field large magnetic entropy changes in the thin film are mainly due to the rapid change in the magnetization near the transition temperature in the easy magnetizing plane. In the $\mathrm{La}_{0.8} \mathrm{Ca}_{0.2} \mathrm{MnO}_{3}$ thin film, there are two exchange interactions, i.e., the intralayer exchange interaction, $\mathrm{J}_{\mathrm{ab}}$, and the interlayer exchange interaction, $\mathrm{J}_{\mathrm{c}}$. Because $\mathrm{J}_{\mathrm{ab}}$ is much stronger than $\mathrm{J}_{\mathrm{c}}$, the magnetic moments tend to lie in the $a b$-plane. In the vicinity of $\mathrm{T}_{\mathrm{C}}$, a small magnetic field along the $a b$-plane can easily promote the paramagnetic to ferromagnetic transition, which causes a rapid change in the

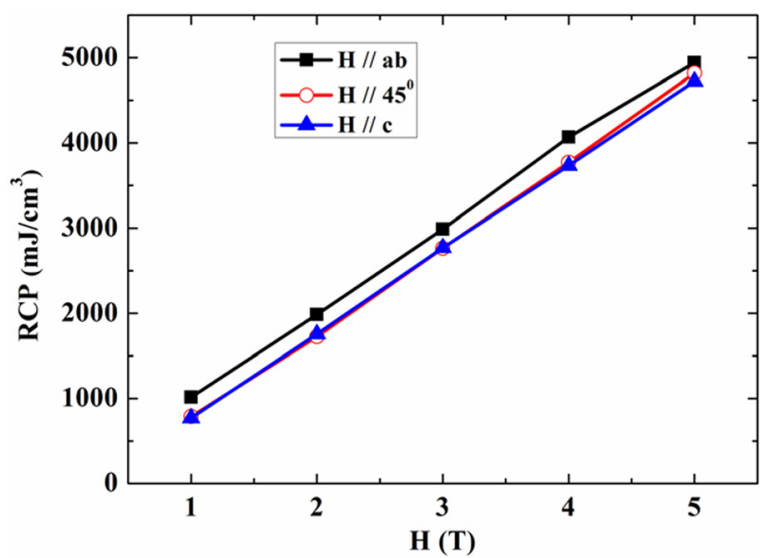

FIG. 7. Relative cooling power of the thin film as a function of magnetic field in different field directions.

magnetization. As a result, a low magnetic field can induce considerable magnetic entropy change.

Relative cooling power (RCP) of the thin film is shown in Figure 7. It shows large RCP values (i.e., $\sim 1000 \mathrm{mJcm}^{-3}$ for the $a b$ plane and $\sim 780 \mathrm{mJcm}^{-3}$ for the $c$-direction), which are higher than those observed in several other perovskite manganites and rare earth alloys. ${ }^{8,10,43}$ One of the interesting features of Figure 6 is that the $\left|\Delta S_{M}\right|$ peaks in all directions are significantly broadened over a wider temperature region than in the corresponding polycrystalline LCMO, due to higher nanostructural disorder. ${ }^{32,33}$ In fact, the observed larger temperature FWHM, $\mathrm{T}_{\mathrm{FWHM}}$, for the peak at low field may indicate that nanostructuring is a potential route for developing magnetic refrigerants with large useful temperature ranges.

\section{CONCLUSIONS}

In this study, MCE of epitaxial $\mathrm{La}_{0.8} \mathrm{Ca}_{0.2} \mathrm{MnO}_{3} / \mathrm{LaAlO}_{3}$ thin film was investigated. In contrast to the bulk form of $\mathrm{La}_{0.8} \mathrm{Ca}_{0.2} \mathrm{MnO}_{3}$ and other perivskites, the magnetic anisotropy, the texture of the material, and film morphology have strong influence on the MCE properties. The $\mathrm{La}_{0.8} \mathrm{Ca}_{0.2} \mathrm{MnO}_{3}$ thin film shows an anisotropic entropy change of 35.9 and $24.97 \mathrm{mJcm}^{-3} \mathrm{~K}^{-1}$ in $1 \mathrm{~T}$ magnetic field change for the $a b$ plane and the $c$-direction, respectively. This larger entropy change value and the enhanced entropy change FWHM is ideal for electronic cooling device. The higher entropy change value and higher RCP with no noticeable hysteresis loss may also make it more convenient for use as a magnetic refrigeration. This indicates that thin film processing might provide an alternative pathway in searching for efficient magnetic refrigerators for microscale systems.

\section{ACKNOWLEDGMENTS}

A.M.S. thanks the NRF-SA (78832) for funding support. J.C.D. acknowledges the FRC and URC of UJ for a Postdoctoral Fellowship under the programme Highly Correlated Matter, supervised by A.M.S. This work was also supported by an Australian Research Council Discovery Project (DP0879070). 
${ }^{1}$ K. A. Gschneidner and V. K. Pecharsky, J. Appl. Phys. 85, 5365 (1999).

${ }^{2}$ K. A. Gschneidner and V. K. Pecharsky, Annu. Rev. Mater. Sci. 30, 387 (2000).

${ }^{3}$ S. Yu. Dan'kov, A. M. Tishin, V. K. Pecharsky, and K. A. Gschneidner, Jr., Phys. Rev. B 57, 3478 (1998); G. V. Brown, J. Appl. Phys. 47, 3673 (1976).

${ }^{4}$ V. K. Pecharsky and K. A. Gschneidner, Appl. Phys. Lett. 70, 3299 (1997).

${ }^{5}$ H. Wada and Y. Tanabe, Appl. Phys. Lett. 79, 3302 (2001).

${ }^{6}$ D. H. Wang, S. L. Tang, H. D. Liu, W. L. Gao, and Y. W. Du, Intermetallics 10, 819 (2002).

${ }^{7}$ A. Fujita, Y. Akamatsu, and K. Fukamichi, J. Appl. Phys. 85, 4756 (1999).

${ }^{8}$ O. Tegus, E. Brück, K. H. J. Buschow, and F. R. de Boer, Nature 415, 150 (2002).

${ }^{9}$ X. Bohigas, J. Tejada, E. del Barco, X. X. Zhang, and M. Sales, Appl. Phys. Lett. 73, 390 (1998).

${ }^{10}$ A. Szewczyk, H. Szymczak, A. Wisniewski, K. Piotrowski, R. Kartaszynski, B. Dabrowski, S. Kolesnik, and Z. Bukowski, Appl. Phys. Lett. 77, 1026 (2000).

${ }^{11}$ M. H. Phan, S. B. Tian, S. C. Yu, and A. N. Ulyanov, J. Magn. Magn. Mater. 256, 306 (2003).

${ }^{12}$ J. C. Debnath, R. Zeng, J. H. Kim, and S. X. Dou, J. Magn. Magn. Mater. 323, 138 (2011)

${ }^{13}$ J. C. Debnath, R. Zeng, J. H. Kim, and S. X. Dou, J. Alloys Compd. 509, 3699 (2011).

${ }^{14}$ M. Bejar, R. Dhahri, E. Dhahri, M. Balli, and E. K. Hlil, J. Alloys Compd. 442, 136 (2007).

${ }^{15}$ M. Koubaa, W. Cheikhrouhou-Koubaa, and A. Cheikhrouhou, J. Phys. Chem. Solids 70, 326 (2009).

${ }^{16}$ W. Cheikhrouhou-Koubaa, M. Koubaa, and A. Cheikhrouhou, J. Alloys Compd. 470, 42 (2009).

${ }^{17}$ V. G. Prokhorov, V. A. Komashko, G. G. Kaminsky, K. K. Yu, S. J. Jun, S. Y. Park, J. S. Park, Y. P. Lee, and V. L. Svetchnikov, Low Temp. Phys. 33, 58 (2007).

${ }^{18}$ K. Chahara, T. Ohno, M. Kasai, and Y. Kozono, Appl. Phys. Lett. 63, 1990 (1993).

${ }^{19}$ R. Bathe, K. P. Adhi, S. I. Patil, G. Marest, B. Hannoyer, and S. B. Ogale, Appl. Phys. Lett. 76, 2104 (2000).

${ }^{20}$ R. Shreekala, M. Rajeswari, S. P. Pai, S. E. Lofland, V. Smolyaninova, K. Ghosh, S. B. Ogale, S. M. Bhagat, M. J. Downes, R. L. Greene, R. Ramesh, and T. Venkatesan, Appl. Phys. Lett. 74, 2857 (1999).

${ }^{21}$ C. M. Xiong, J. R. Sun, Y. F. Chen, B. G. Shen, J. Du, and Y. X. Li, IEEE Transactions on Magnetics 41, 122 (2005); R. E. Treece, P. Dorsey, M. Rubinstein, J. M. Byers, J. S. Horwitz, E. Donovan, and D. B. Chrisey, MRS Proceedings 384 (1995).

${ }^{22}$ R. Von Helmolt, J. Wecker, B. Holzapfel, L. Schultz, and K. Samwer, Phys. Rev. Lett. 71, 2331 (1993).
${ }^{23}$ Y. Sun. M. B. Salamom, and S. H. Chun, J. Appl. Phys. 92, 3235 (2002).

${ }^{24}$ P. Raychaudhuri, S. Mukherjee, A. K. Nigam, J. John, U. D. Vaisnav, R. Pinto, and P. Mandal, J. Appl. Phys. 86, 5718 (1999).

${ }^{25}$ A. Goyal, M. Rajeswari, R. Shreekala, S. E. Lofland, S. M. Bhagat, T. Boettcher, C. Kwon, R. Ramesh, and T. Venkatesan, Appl. Phys. Lett. 71, 2535 (1997)

${ }^{26}$ S. Jin, T. H. Tiefel, M. McCormack, R. A. Fastnacht, R. A. Fastnacht, R. Ramesh, and L. H. Chen, Science 264, 413 (1994).

${ }^{27}$ M. McCormack, S. Jin, T. H. Tiefel, R. M. Fleming, J. M. Philips, and R. Ramesh, Appl. Phys. Lett. 64, 3045 (1994).

${ }^{28}$ T. Mukherjee, S. Sahoo, R. Skomski, D. J. Sellmyer, and Ch. Binek, Phys. Rev. B 79, 144406 (2009).

${ }^{29}$ D. T. Morelli, A. M. Mance, J. V. Mantese, and A. L. Micheli, J. Appl. Phys. 79, 373 (1996).

${ }^{30}$ S. Thota, Q. Zhang, F. Guillou, U. Luders, N. Barrier, W. Prellier, A. Wahl, and P. Padhan, Appl. Phys. Lett. 97, 112506 (2010).

${ }^{31}$ R. Skomski, Ch. Binek, S. Michalski, T. Mukherjee, A. Enders, D. J. Sellmyer, J. Appl. Phys. 107, 09A922 (2010).

${ }^{32}$ C. W. Miller, D. V. Williams, N. S. Bingham, H. Srikanth, J. Appl. Phys. 107, 09A903 (2010).

${ }^{33}$ V. Recarte, J. I. Perez-Landazabal, V. Sanchez-Alarcos, V. A. Chernenko, M. Ohtsuka, Appl. Phys. Lett. 95, 141908 (2009).

${ }^{34}$ X. Moya, L. E. Hueso, F. Maccherozzi, A. I. Tovstolytkin, D. I. Podyalovskii, C. Ducati, L. C. Phillips, M. Ghidini, O. Hovorka, A. Berger, M. E. Vickers, S. S. Dhesi, and N. D. Mathur, Nature Mater. 12, 52 (2013).

${ }^{35}$ T. K. Nath, R. A. Rao, D. Lavirc, C. B. Eom, L. Wu, and F. Tsui, Appl. Phys. Lett. 74, 1615 (1999).

${ }^{36}$ L. Ranno, A. Llobet, R. Tiron, and E. Favre-Nicolin, Appl. Surf. Sci. 188, 170 (2002).

${ }^{37}$ S. D. Bader, Rev. Mod. Phys. 78, 1 (2006).

${ }^{38}$ R. D. McMichael, R. D. Shull, L. J. Swartzendruber, L. H. Bennett, and R. Watson, J. Magn. Magn. Mater. 111, 29 (1992).

${ }^{39}$ P. F. Xu, S. H. Nie, K. K. Meng, S. L. Wang, L. Chen, and J. H. Zhao, Appl. Phys. Lett. 97, 042502 (2010).

${ }^{40}$ J. Wang, F. X. Hu, R. W. Li, J. R. Sun, and B. G. Shen, Appl. Phys. Lett. 96, 052501 (2010).

${ }^{41}$ K. Daoudi, T. Tsuchiya, I. Yamaguchi, T. Manabe, S. Mizuta, and T. Kumagai, J. Appl. Phys. 98, 013507 (2005).

${ }^{42}$ R. A. Rao, D. Lavric, T. K. Nath, C. B. Eom, L. Wu, and F. Tsui, Appl. Phys. Lett. 73, 3294 (1998).

${ }^{43}$ Z. B. Guo, Y. W. Du, J. S. Zhu, H. Huang, W. P. Ding, and D. Feng, Phys. Rev. Lett. 78, 1142 (1997).

${ }^{44}$ M. H. Phan, V. T. Pham, S. C. Yu, J. R. Rhee, and N. H. Hur, J. Magn. Magn. Mater. 272, 2337 (2004).

${ }^{45}$ S. K. Banerjee, Phys. Lett. 12, 16 (1964).

${ }^{46}$ K. A. Gschneidner, V. K. Pecharsky, and A. O. Tsokol, Rep. Prog. Phys. 68, 1479 (2005). 